Portland State University

PDXScholar

6-9-1975

\title{
Exteroceptive influence on a marihuana induced conditioned taste aversion
}

\author{
Albert William Greenwood \\ Portland State University
}

Follow this and additional works at: https://pdxscholar.library.pdx.edu/open_access_etds

Part of the Biological Psychology Commons, and the Experimental Analysis of Behavior Commons Let us know how access to this document benefits you.

\section{Recommended Citation}

Greenwood, Albert William, "Exteroceptive influence on a marihuana induced conditioned taste aversion" (1975). Dissertations and Theses. Paper 2154.

https://doi.org/10.15760/etd.2152

This Thesis is brought to you for free and open access. It has been accepted for inclusion in Dissertations and Theses by an authorized administrator of PDXScholar. Please contact us if we can make this document more accessible: pdxscholar@pdx.edu. 


\section{AN ABSTRACT OF THE THESIS OF Albert William Greenwood for the Master of Science in Psychology presented June 9, 1975.}

Title: Exteroceptive Influence on a Marihuana Induced Conditioned Taste Aversion.

APPROVED BY MEMBERS OF THE THESIS COMMITTEE:

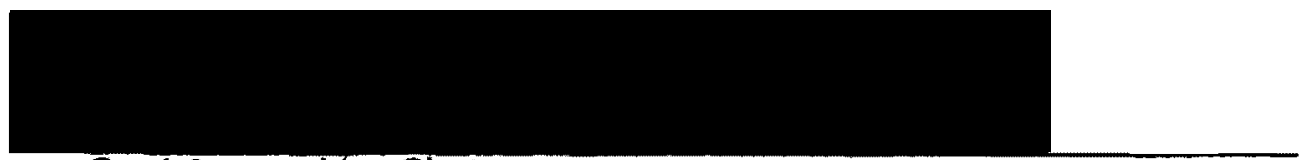

Cord Sengstake, Chairman

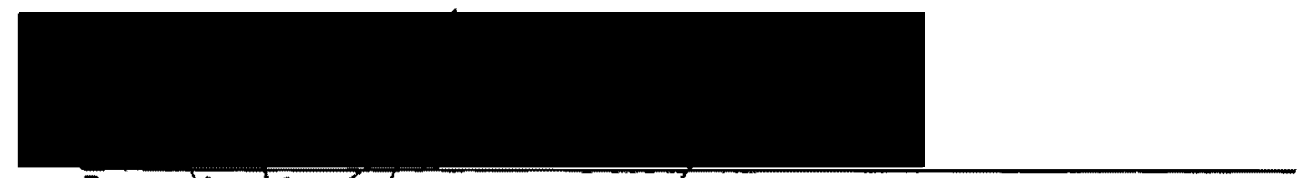

Roger Jenhings

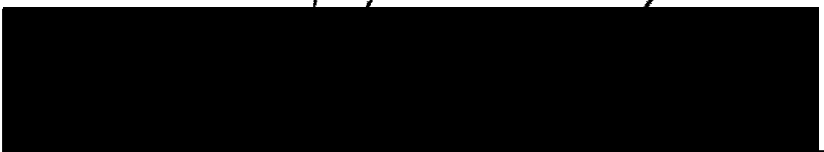

Hugo Mànard

Forty-five male, Sprague Dawley rats were used to determine if external stimuli could influence the length of a conditioned taste aversion. Animals were given a novel taste (sucrose), and then injected with one of three different substances, marihuana, LiCl, or saline. The animals were then placed into either a stimulation condition, a non-stimulation condition, or returned to the home cage. The stimulation condition contained aversive stimuli in the form of bright, flashing lights and loud noises. The other conditions had no aversive stimulation. It was expected that the animals receiving injections of marihuana would have an 
increase in their responsiveness to events in their environment, and thus be more sensitive to the aversive stimulation. By reacting to not only the internal toxicosis, but also the aversive external stimulation, it was hoped that the animals would undergo a more totally aversive experience in the stimulation condition. This increase in discomfort with the addition of external aversive stimuli was expected to be reflected in the development of longer conditioned aversions in animals receiving the marihuana and stimulation. The $\mathrm{LiCl}$ group was expected to show no reactiveness to the external aversive stimuli. Although faste aversions did develop in the marihuana and $\mathrm{LiCl}$ groups, no differences were found between treatment conditions nor between toxins. This study shows that external aversive stimuli do not play a role in an animal's conditioned aversion to sucrose after injection of a toxic drug such as marihuana or $\mathrm{LiCl}$. 


\title{
EXTEROCEPTIVE INFLUENCE ON A MARIHUANA INDUCED \\ CONDITIONED TASTE AVERSION
}

\author{
by
}

ALBERT WILLIAM GREENWOOD

\begin{abstract}
A thesis submitted in partial fulfillment of the
requirements for the degree of
\end{abstract}

\author{
MASTER OF SCIENCE \\ in \\ PSYCHOLOGY
}

Portland State University

1975

5 


\section{TO THE OFFICE OF GRADUATE STUDIES AND RESEARCH:}

The members of the Committee approve the thesis of

Albert William Greenwood presented June 9, 1975.

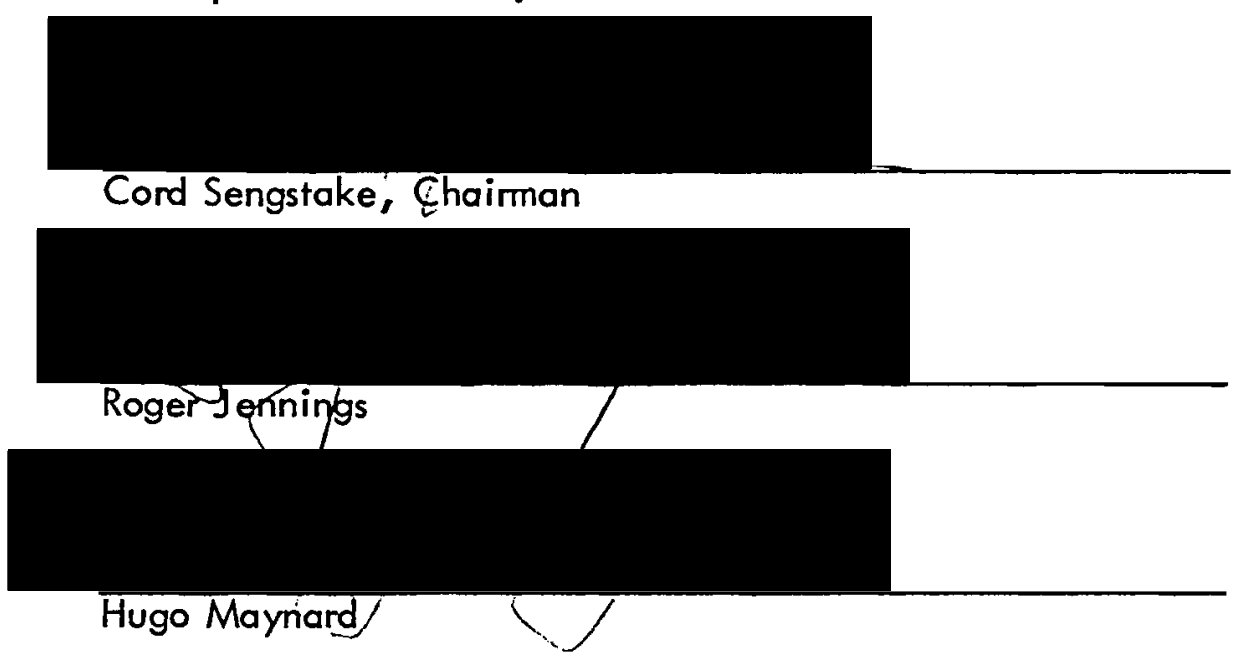

\section{APPROVED:}

Ronald E. Smith, Head, Department of Psychology

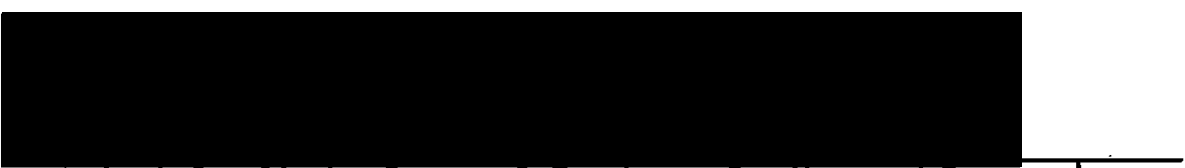

Dávid G. Clark, Dean of Graduate Studies and Research

June 9, 1975 
TABLE OF CONTENTS

PAGE

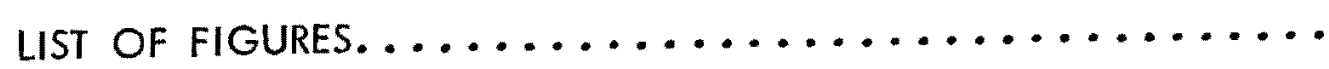

CHAPTER

I INTRODUCTION ................... I

II METHODS....................... 10

III RESULTS ....................... 14

i DISCUSSION $\ldots \ldots \ldots \ldots \ldots \ldots \ldots \ldots \ldots \ldots \ldots \ldots$

BIBLIOGRAPHY $\ldots \ldots \ldots \ldots \ldots \ldots \ldots \ldots \ldots \ldots \ldots \ldots \ldots \ldots \ldots \ldots$ 


\section{LIST OF FIGURES}

FIGURE

PAGE

1 Mean Sucrose Consumption of Animals in the Marihuana

Toxin Group ....................

2 Mean Sucrose Consumption of Animals in the $\mathrm{LiCl}$ Toxin

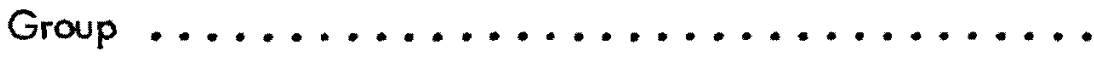

3 Mean Sucrose Consumption of Animals in the Saline

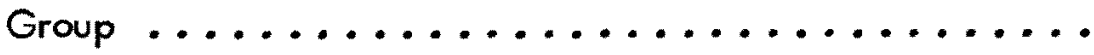




\section{CHAPTER I}

\section{INTRODUCTION}

A number of studies have been conducted exploring the phenomena of conditioned taste aversions. If an animal consumes a novel substance and afterwards is made sick, it will develop an aversion to that new taste. The development of the aversion was thought to be much like an operant conditioning process. The animal would learn a conditioned avoidance response to the novel taste by associating it with the aversive stimulus (Revusky and Garcia 1970). More recent studies have revealed two important departures from traditional learning and conditioning models. Only one pairing of the new taste and an aversive stimulus is needed for an aversion to develop (Hargrave and Bolles 1971). This one trial learning tends to diminish the importance of the concept of reinforcement in a learning situation of this type. In addition, the emphasis moves away from the immediacy of the reinforcement as a requirement for learning. Aversions will develop with delays in excess of 12 hours between ingestion of the novel substance and the aversive stimulus (Smith and Roll 1967, Revusky 1968).

There are some important criteria that must be satisfied for the aversion to develop. The taste must be a novel one or no association between taste and illness will occur (Rodgers and Rozin 1971). A number of novel tastes have been used in previous studies (Revusky and Garcia 1970). The most effective seem to be those 
for which the animal has an innate preference such as sucrose (Beck and Nash 1969).

The relevance of a stimulus is also an important factor (Dietz and Capretta 1967, Revusky and Garcia 1968). When the cue in a conditioned aversion is a flavor (as in a taste aversion), a high associative strength develops to physiological (internal) aftereffects while an association between taste and events originating from the external environment is weak. Similarly, external cues such as shock are associated with other external events (lights or noise for example), but not with internal events such as toxicosis:

Some recent experiments clarify the role that internal and external stimuli play in a taste aversion. Garcia and Koelling (1966) used toxicosis as an internal punishment and compared it with internal and external cues. In addition, they also paired these cues with an external punishment using electric shock. They found that a pairing of taste with toxicosis produced a taste aversion while taste paired with the shock did not. By pairing the external cue with the shock, however, an aversion did develop and as expected, the combination of external cue and toxicosis produced no aversion. Garcia, McGowan, Ervin and Koelling (1968) used size of food pellets and flavor as cues and compared them with internal and external punishment. Again, toxicosis was associated to a flavor but not to size of a food pellet, while size was related to shock but not toxicosis. These data suggest that an aversion develops when the cue and consequence are of a similar nature. In other words, an internal-internal pairing of events will produce a conditioned aversion while an internal-external combination will not. 
Revusky and Garcia (1970) have developed a model that utilizes the information in the data discussed above. They suggest that an animal develops an aversion to a new taste because it associates the cue (taste) with its toxicosis (the aversive stimulus). No association is made between a taste and aversive stimuli from the external environment, since it is unlikely that ingestion of a substance would create discomfort that came from an animal's surroundings. They imply that an animal is able to rule out events that could not be consequences of, or related to, a taste. According to their model, since ingestion of a taste is an internal event, events in the environment (which are external) would have no role in the development of the aversion.

From the data presented, it is apparent that animals have the capacity to be selectively responsive to relevant and irrelevant stimuli. This suggests that there is some well developed mechanism that enables the rat to discriminate between events with different consequences. The impact of this discriminatory process does not seem too great when one considers only that the animal can differentiate between external and internal types of activity. It does become more interesting, however, when one considers the possibility that effects may not always be distinctly internal or external in origin.

It is reasonable to assume that many stimuli have exclusive consequences i.e. an external event has effects upon the animal which are clearly external. It is not wise, however, to rule out the notion that an external stimulus may influence an internal process. An interaction could exist between internal and external activity under appropriate circumstances. The idea of interaction suggests that the 
difference between internal and external types of activity would not be readily distinguishable. Specifically, that the effects of internal and external stimulation might be confounded to an animal if interaction did occur. In this instance it would mean that perhaps an external event could be involved in an association between internal events.

Acknowledging the possibility of an interaction of effects in a conditioned taste aversion does not dispute the necessity of an internal-internal pairing as proposed by Revusky and Garcia. From the data presented it does seem clear that animals will not associate internal and external events and thus the internalinternal pairing requirement is well founded. It is probable though, that the external environment could influence the results of an internal-internal pairing of events. Would manipulation of the external environment somehow alter the results of a conditioned taste aversion? If so, it would be evidence that an interaction can occur between internal and external activity during formation of a conditioned taste aversion.

This matter may be easier to understand using the following examples: Lithium Chloride is a drug which has been used successfully in taste aversions (Nachman 1973). Its primary site of action seems to be in the gastro-intestinal region (Goodman and Gillman 1970). Since this drug does not appear to affect an animal's sensory systems, it is doubtful that the drug increases reactivity to the external environment. Due to the drug's distinctly gastro-intestinal effects, the chance for an interaction to occur seems relatively small. Any aversive activity 
that occurred in the environment would likely be easily identifed as separate from the internal discomfort felt as a result of $\mathrm{LiCl}$.

Marihuana has also been used in taste aversion studies as an aversive consequence (Ellsmore 1972, Chambers and Sengstake 1973). One might assume, since marihuana can be successfully associated with a taste, that the aversive nature of marihuana is a result of the effect it has upon an animal internally. This is a logical assumption in consideration of prior research yet it may be presumptuous to say that the effects are exclusively internal. In actuality, the nature of the effects of marihuana upon an animal is not clear. It is conceivable that marihuana's influence on an animal may make it susceptible to external activity as well.

Rats are known to be sensitive to loud noise. They react to it in a fearful manner and it has been shown to have an aversive effect upon them (Campbell 1968). After being given marihuana, they seem to become more sensitive to noise (Wetle 1971). There is often an increase in urination and the animals may crouch or assume an avoidance type of posture. The overall behavior is indicative of an increase in the fear of noise (Hall 1934, 1941). What this seems to suggest is that while under the influence of marihuana external events can alter the state of discomfort that an animal is experiencing. From this visual observation, it appears that marihuana increases an animal's reactivity to the environment. Perhaps there is some effect from the drug which affects the animal's sensitivity to external events. 
Further evidence that marihuana may affect response to environmental stimuli appears in the literature on the sensory effects of marihuana. A multitude of reactions have been reported which include panic and delusional thinking (Keeler 1967), an increase in audio and visual sensitivity (Tart 1971), facilitation in learning and acquisition (Tart 1971), and the precipitation of psychosis (Isbell 1967). These effects may be attributed to, and vary with the concentration of active ingredient delta-9-tetrahydrocannabinol (THC) in the drug at the time of administration. The information gathered about sensory changes has been limited to research with human subjects, yet it does appear that marihuana may change the reactiveness of subjects to external events. Another interesting point is that aversive effects must be considered a part of the overall marihuana syndrome (Bromberg 1934). Many of the effects seem to be of a sensory nature and therefore must have some connection with external events.

Bringing the knowledge we have about marihuana together three things become clear: 1) the drug has some aversive effect upon the rat which may be attributed in part to internal activity; 2) behavior changes in the rat after intake of marihuana and they appear to be more responsive to activity in their environment; 3) sensory changes which may be aversive in nature are reported as an effect of the drug. It would seem that marihuana is a drug which may ultimately influence responsiveness to both internal and external activity. If this is so, marihuana would be a useful substance to use in an attempt to highlight the interaction of internal and external processes. 
As stated earlier, one should not dispute the fact that marihuana has some internal effects upon an animal. The fact that marihuana seems to increase an animal's reactivity to the environment brings up the possibility that an alternation of external events could influence the total effect of the drug on the animal. If the proper toxins are employed, is it possible for external stimuli to become part of the total illness syndrome that occurs due to the aversive stimulus?

It has been shown that the length of a conditioned taste aversion is dependent in part upon the intensity of the aversive stimulus (Revusky 1968, Dragoin 1971). The time required for the animal to return to normal drinking levels (extinction) increases in proportion to the strength of the punishment. This phenomenon can be seen when marihuana and $\mathrm{LiCl}$ are used in a conditioned taste aversion. Two questions arise: Would the presence of aversive stimulation in addition to the existing internal discomfort produced by a toxin have an additive affect, making the total experience more aversive to the animal? Would making the total experience more aversive affect the extinction rate much the same as an increase in strength of the aversive stimulus?

If an interaction was to occur between internal and external events the possibility of obtaining a more totally aversive condition seemslikely. In addition, a more aversive condition should produce longer extinction periods. A comparison between a group receiving both internal and external stimuli and a group receiving either internal or external stimuli could be used to detect if indeed; 1) an interaction between internal and external will result in a more totally aversive condition and 2) the use of aversive stimuli from the environment 
could mimic the effects of an increase in strength of the internal aversive consequence alone.

Marihuana has al ready been introduced as a drug which would highlight the interaction existing between internal and external events. It is therefore a good candidate for use as an aversive stimulus in a conditioned taste aversion to detect evidence of an interaction. There is sufficient evidence available for one to assume that marihuana may affect sensory systems in a way to make the animals more susceptible to external events.

A study using marihuana as the toxic agent in a conditioned taste aversion would serve a dual purpose. It would be a nice way to explore the effects that marihuana has upon the rat by examining the role of internal and external events as aversive stimuli. Secondly it would be a measure to test the exteroceptive and interoceptive discriminatory capacity proposed by Revusky and Garcia. By creat- . ing a situation where the potential for an interaction to occur is very likely (using marihuana), it may become more difficult for an animal to differentiate exactly what events are producing the discomfort it is feeling. A study using marihuana would test the limits of the capacity to discriminate and may shed some light on the apparent sensitivity of the discriminatory system.

$\mathrm{LiCl}$ has also been mentioned as a drug from which a distinction would most likely be made between its internal effects and any stimulation from external sources. It would be useful to compare the extinction periods of this drug and those of marihuana under similar conditions. External events should not influence the discomfort produced by $\mathrm{LiCl}$ and if differences between the two drug groups 
were seen, it would lend credence to our ideas about interaction of internal and external stimuli and the effects of marihuana upon that interaction.

The design of the experiment would focus on a manipulation of the animal's environment. Two treatment conditions (environments) could be used. An environment that is aversive to the rat could be employed using external stimuli that would increase the animal's discomfort. We know that rats react adversely to loud or sudden noise. Consequently this would be a useful stimulus in creating an aversive external condition. To enhance the stimulation of sensory systems a number of flashing lights might also be utilized as negative stimulation. Even though the rat is not able to see well and does not have good pattern vision, the startling effect of sudden bursts of light would probably contribute to an aversive condition.

Another condition would be set up to minimize the aversive nature of the animal's environment. The emphasis here would be to decrease the activity in the external surroundings so that there would be less chance for external events to influence the development of the aversion to the taste.

If marihuana increases an animal's reactivity to the environment which in turn makes them more susceptible to external events, one might expect to see animals in the stimulation condition develop greater aversions to the novel taste. In animals receiving $\mathrm{LiCl}$ the effects of the stimulation condition should be negligible. We would therefore also be able to test the idea that external activity will have no effect upon an aversion using $\mathrm{LiCl}$ as a toxin. 


\section{CHAPTER ॥}

\section{METHODS}

Animals used in this experiment were adult ( 90 to 120 days) male, Sprague Dawley derived rats. All were naive to experimental conditions. The animals were housed in individual cages and given ad lib food and water. Fresh water was offered at the beginning of the night cycle. Graduated cylinders with sipper tubes were used during this time to accustom the animals to drinking from them: These same fubes would be used during the actual testing. There were nine experimental groups, five animals to each group. All were weighed and handled daily for two weeks prior to the experimental period.

Three different drugs were used as taxins. Delta-9-tetrahydrocannabinol (THC) was mixed with a solution of $0.9 \% \mathrm{NaCl}(w / v)$ in distilled water and $4.0 \%$ tween-80 (polyoxyethylene sorbitan mono-cleate) $(v / v)$, administered at a dosage level of $3 \mathrm{mg} / \mathrm{kg}$ of body weight. Injection volume was $1 \mathrm{ml} / \mathrm{kg}$. A second group received injections of the carrier solution (tween-80 and saline). A third group was given a .3 Molar solution of $\mathrm{LiCl}$ injected at a volume of $10 \mathrm{ml} / \mathrm{kg}$. All solutions were given by $i . p$. injection.

The discrepancy between volume levels of the $\mathrm{LiCl}$ and the other drug groups at the time of injection was felt to be justifiable for the following reasons. $\mathrm{LiCl}$ can cause severe pain to the gastro-intestinal region of the rat if it is administered in concentrations larger than .3 Molar (Nachman and Ashe 1973). 
This pain in itself might affect the conditioned aversion by acting as an aversive stimulus. In addition the fluid volume of an injection does not seem to influence a conditioned aversion (Chambers, personal communication). In light of this information it is reasonable and safer to utilize the .3 Molar solution which has been used successfully in previous taste aversion studies (Nachman and Ashe 1973).

Three treatment conditions were used in the study, a stimulation condition, a non-stimulation condition, and a cage condition. Animals in the stimulation condition were placed in a plywood box (17 × $17 \times 24$ inches). with a ventilation hole three inches in diameter at one end. The inside of the box was painted white to increase the reflectance. Noise and light were used as the aversive stimuli. The light stimulus consisted of two 6.5 volt light bulbs mounted to the top of the box. The lights were connected to a circuitry which enabled them to go on and off at aperiodic intervals. While on, the lights would flash at the rate of four flashes per second. For the noise stimulus, a three inch speaker was mounted to the ceiling wired to a stereo tape recorder. An aperiodic series of loud, sudden noises made by a bicycle horn and whistle were recorded on the tape. The noise was presented at a high intensity to the animals. The animals appeared to be extremely distressed when exposed to these noises. The suddenness of the noise and its volume level seemed to increase the aversive nature of the stimulus.

After the animal was placed in the stimulation box, the box was latched and room lights were turned off so the animal was in virtual darkness. Both the 
tape and light circuitry were turned on simultaneously and run for a two hour period.

A box identical to that described above was used for the non-stimulation condition. The difference here was that neither noise nor lights were introduced during the two hour period. Instead the animal remained in darkness and silence for the entire time.

The animals remained in their original cages during the experimental period. The cages were covered with a wire mesh screen to prevent the animal from jumping out. At the end of the two hour test period, the animals were returned to the vivarium where they were kept for the remainder of the experimental period.

A third group of animals was returned to the vivarium at the beginning of the experimental period. These animals remained in their original cages.

On day 1 (acquisition), a $10 \%(w / v)$ solution of sucrose was offered as a novel taste at the beginning of the night cycle. After two hours the consumption was recorded and the sucrose removed. Animals that had drunk less than $5 \mathrm{cc}$ during this time were rejected from the experiment (three animals were rejected and replaced with standby animals which had received identical preparation). The 5cc minimum was established so that; 1) it would be safe to assume that the animal liked sucrose to begin with and 2) an original consumption level could be obtained which would be high enough to displ ay the drop in drinking level if an aversion did develop. During a thirty minute "injection period" immediately following the two hour consumption period, the animals were moved outside the vivarium and 
injected with one of the three drug solutions. All animals were randomly chosen for drug group, testing condition, and order of injection. At the end of the injection period, animals were placed in one of the previously described conditions. Animals were then re-tested for sucrose consumption at the start of the night cycle on day 3 (extinction). A forty eight hour period between the offering of sucrose on day 1 and day 3 was to insure that the animals were experiencing no toxic effects from the drugs given on day 1 . If still feeling some illness on day 3 , the animals might not give a true indication of their like or dislike of the sucrose. Measurements were taken on days 3-25. Animals were considered to be out of their aversion when on any day consumption totaled two thirds of the amount ingested on acquisition day (day 1 ).

Although weighing was discontinued on the first extinction day, a post experimental weighing was used to check for any radical loss of weight which might indicate some type of illness. None was found and it was assumed all animals were healthy throughout this experiment. 


\section{CHAPTER III}

\section{RESULTS}

A 2 factor analysis of variance with repeated measures over days was used to detect differences between day 1 and day 3 levels of sucrose consumption. A significant difference within toxin over time was evident $(F(2,36)=8)$. The substantial difference in consumption levels indicates that a taste aversion did develop in those animals receiving Delta-9 and $\mathrm{LiCl}$. The consumption levels of animals in the saline group remained essentially the same between days 1 and 3 .

A 2 way analysis of variance was used to examine treatment effects in the Delta-9 and $\mathrm{LiCl}$ groups. No significant differences were found between the treatment conditions $(F(2,24)=.13)$ nor between toxins $(F(1,24)=3.4)$. The interaction was also non-significant $(F(2,24)=.66)$. Consumption of sucrose seemed the same regardless of which toxin or treatment an animal was subjected to.

Examination of sucrose consumption during extinction revealed a large variance in the duration of the aversive effect. Some animals resumed their baseline consumption rate quite rapidly after their initial drop in sucrose consumption. Other animals developed extremely long aversion periods (up to 40 days). There appears to be no correlation between this variance and any experimental factors. 


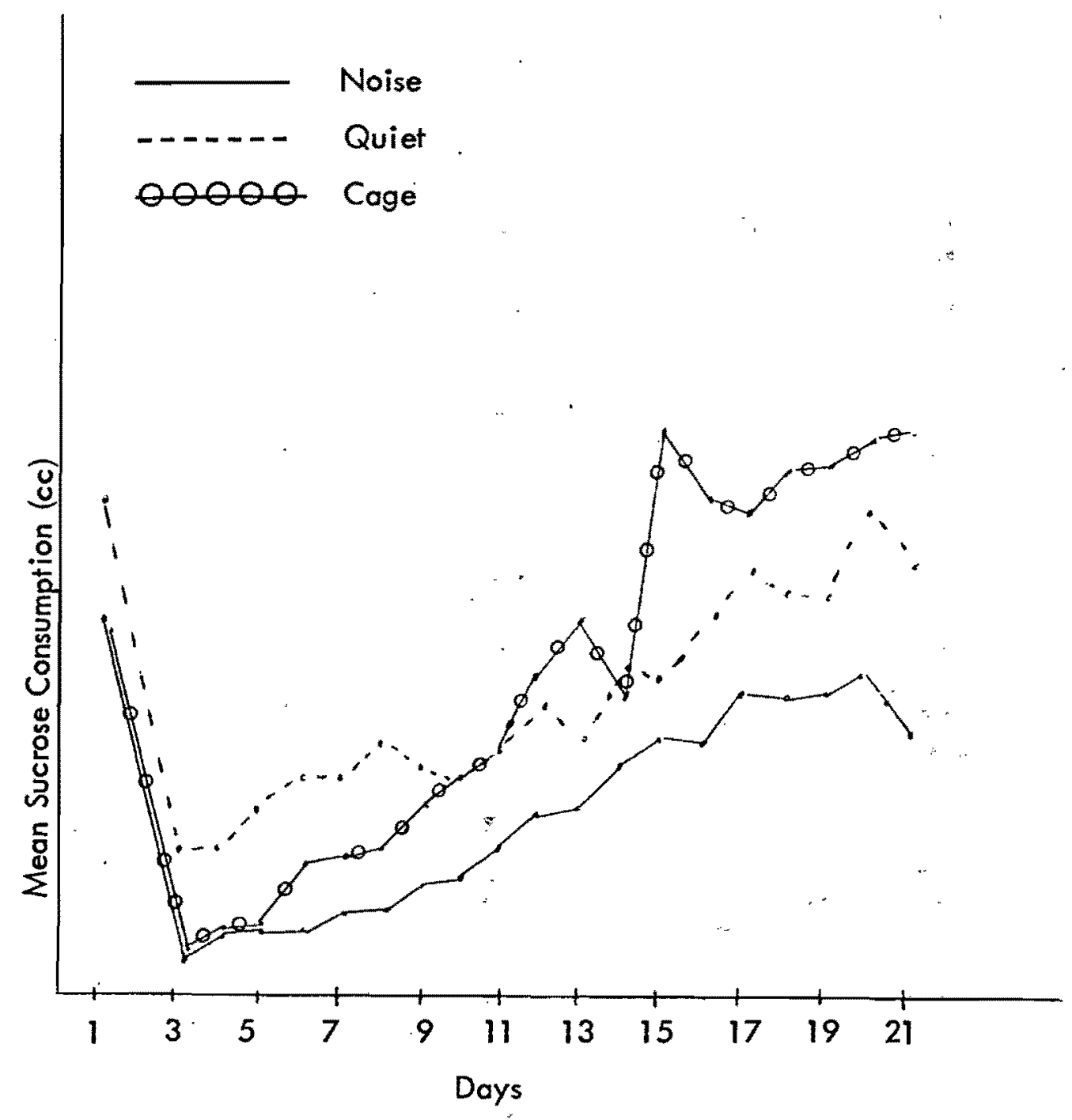

Figure 1. Mean sucrose consumption of animals in the marihuana toxin group 
16

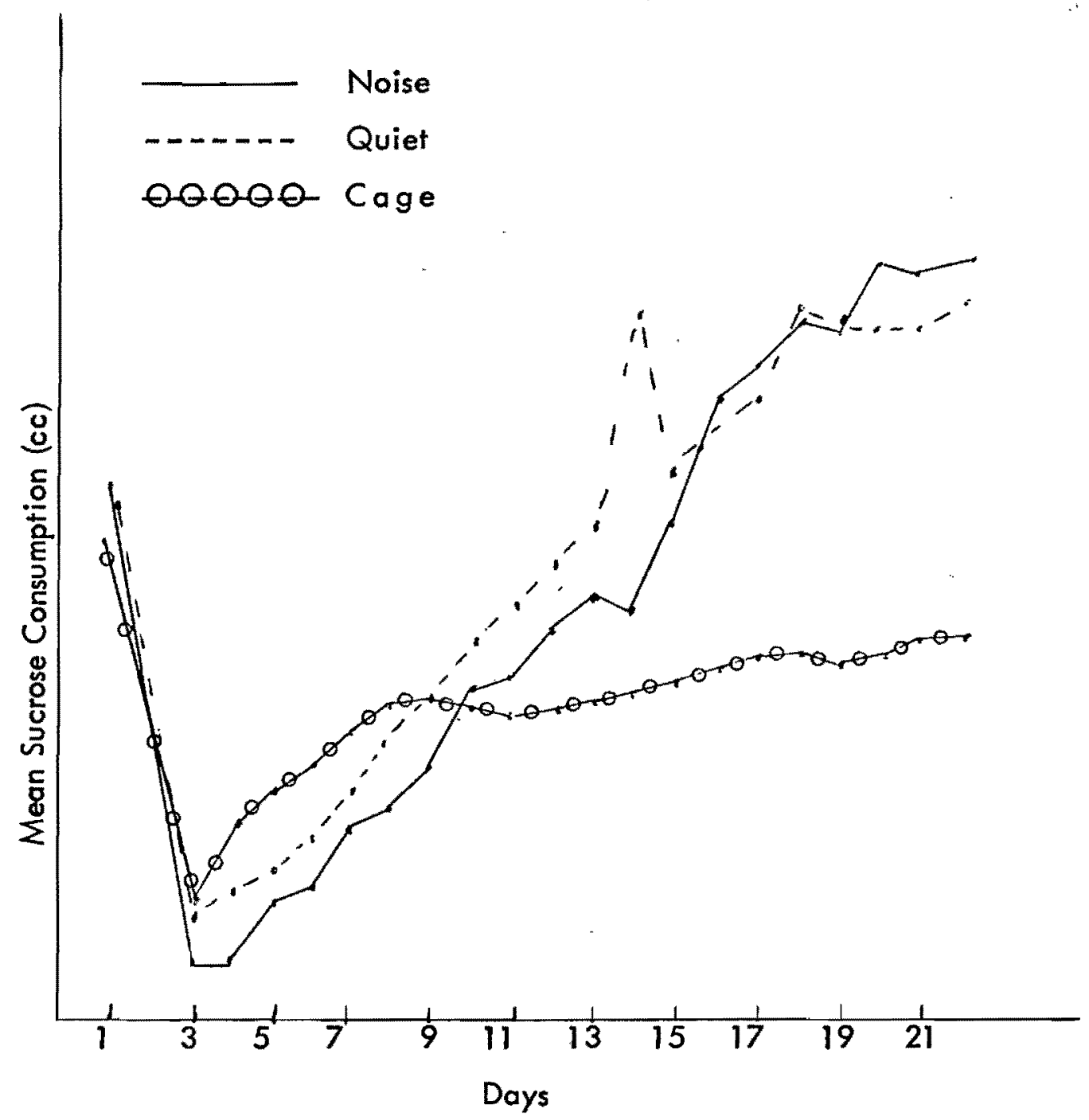

Figure 2. Mean sucrose consumption of animals in the $\mathrm{LiCl}$ toxin group 


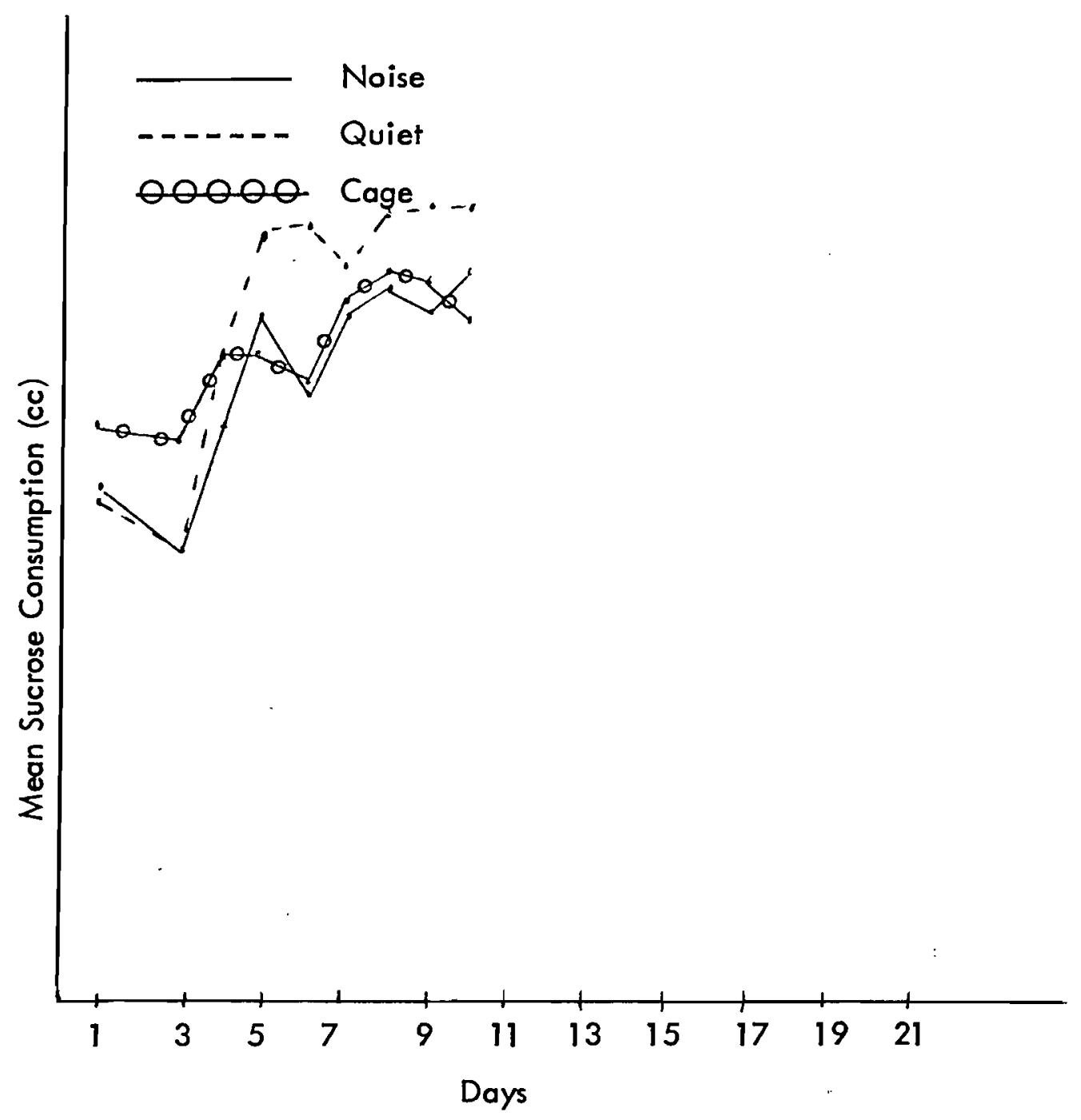

Figure 3. Mean sucrose consumption of animals in the saline group 


\section{CHAPTER IV}

\section{DISCUSSION}

This study indicates it is not possible to noticeably affect sucrose consumption in a conditioned taste aversion by introducing aversive external stimulation. Whatever discomfort the animal was experiencing from the effects of marihuana, was not associated with the noise and lights. An attempt was made to produce a more totally aversive experience by combining internal and external aversive stimuli. It was hoped that any increase in discomfort would be reflected in longer extinction periods in the animals' aversions. The fact that no differences were seen between treatment conditions enables one to make the following assumptions: 1) the existence of some interaction between internal and external consequences in a taste aversion is questionable; 2 ) the animals seem to be able to discriminate the internal discomforting effects of a toxicosis from aversive stimuli of external origin.

We were not attempting to detect an association between internal cues and external consequences. * We did try to influence the internal effects of the toxin which were already occurring in the animal by manipulation of the environment. Apparently the interaction of internal and external events which would have made

*In a conditioned taste aversion the novel taste may be considered the cue. The subsequent toxicosis may be considered a consequence of that cue. In this particular study the external aversive stimulation would also be a consequence if interaction occurred. 
the origin of an animal's discomfort harder to distinguish, did not occur or if it did, not to the extent that was expected. When considering why the interaction did not become a factor in this study two questions come up: 1) Was marihuana a reasonable choice as a toxin which would increase an animal's reactivity to both internal and external events? 2) Was the external stimulus aversive enough to be of significant discomfort to the animal?

From previous research there are indications that marihuana does enhance an animal's susceptibility to external stimulation (Wetle 1971). That fact seems to be supported by some visual observations made during this study.

Although the external sensory stimulation had no observable effect upon sucrose consumption, the noise condition did seem to have an effect upon the animals themselves. Usually when the animals were removed from the stimulation condition they seemed extremely anxious, were hunched over, and had their fur raised. Since such behavior usually indicates distress, it was likely that there was indeed some adverse effect upon the animals while in the treatment condition. Unfortunately, the treatment conditions were set up in such a way that visual observation of the rats in the experimental space was impossible. Considering the variance that was observed in the animals' drinking, it would have been interesting to watch how the animals reacted to the aversive stimulus. Some appeared to be more adversely affected by the treatment than others. Valuable information might have been obtained had the animals' behavior both during and immediately after the test period been recorded. It is possible that owing to individual differences or other unknown factors, the animals that appeared most 
visually disturbed could have developed the longest aversions. As it was, there was no way of exploring this possible connection.

Even though the treatment conditions (noise and toxin) were aversive separately, no association between the two was established. This supports the notion that the animal is able to discriminate between internal and external types of stimulation. In using marihuana, the potential for some kind of interaction to occur was intensified. In essence, we were testing the limits of this discriminative capacity. The fact that the animal did not respond to the external discomfort it was experiencing by decreasing its sucrose consumption further, indicates a well developed discriminative ability. The fact that this differentiation occurs also enhances the role that stimulus relevance plays in taste aversions. The animal is seemingly able to associate a consequence if it is relevant to the cue. Since the animals did not respond to the external aversive stimulation, it was apparently irrelevant. In other words, the animal did not equate the discomfort experienced due to the loud noise and bright lights with the ingestion of the sucrose.

Once again the question may arise, would there be a way to make the external activity more relevant? It may have been possible to increase the animals' sensitivity to the environment by giving them larger doses of marihuana. The $3 \mathrm{mg} / \mathrm{kg}$ dosage was chosen to have a moderate toxic effect; too high a dose could have been so aversive to the animals that external effect would be minimized. In other words, an animal that is made extremely sick might reach a point where it cannot become appreciably more uncomfortable. In this way it might not be 
receptive to additional aversive stimuli such as noise and lights. The dosage used was thought to be one that would produce toxic effects yet would enable the animal to be sensitive to external changes in the environment.

Some attention needs to be given to the assumption that external effects would act much like an increase in dosage level. By combining the internal and external aversive stimulation in one treatment condition we hoped we could simulate a larger dose of marihuana. If a discomfort was perceived as greater because of the external stimuli, the length of the conditioned aversion should increase. One difficulty in making a substitution of that kind is that we are unable to assess how much of an increase in dosage would be needed to increase the length of an aversion. We are aware that the dosage/aversion effect is linearly correlated (Revusky 1968, Dragoin 1971). In fine measurement, however, would an increase of say $.5 \mathrm{ml} / \mathrm{kg}$ affect the length significantly? We therefore run into the problem again of how much more aversive the stimulation condition would have to be to differentiate it from the quiet condition. It may be that the difference we tried to see (i.e. a difference in extinction time) cannot adequately be produced by leaving the dosage the same. Perhaps external types of stimulation cannot increase the toxic effect of a drug to a point where it will be observably greater.

Some of the questions raised by this experiment may be starting points for additional research. To become more knowledgeable about toxic effects might enable us to understand more about taste aversions. One might want to explore aversion lengths, using marihuana as the toxic substance. A study could be 
conducted to examine the changes in aversion length due to dosage, concentrating on the subtlety of the dosage change. It would be useful to see how much more of a drug has to be administered to observe significant changes in sucrose consumption.

Utilizing the information gained concerning the animals' discriminatory capacities, one might be encouraged to find out more about how marihuana and the environment affect behavior. To focus on external cues and consequences rather than attempting to differentiate internal and external as in this study, may tell us more about aversive external stimulation. One way to measure something other than internal activity would be to place the animals in a performance situation after an external aversive condition such as the stimulation treatment in this study. One might see a difference in responsiveness, orientation, or learning ability due to the aversive effects of an external nature.

We are now able to understand more about the role that external stimulation has when used as an aversive consequence in a taste aversion. Caution must be used, however, in interpreting what has been learned about marihuana. Even though external effects are seen as irrelevant in a taste aversion, the idea that external stimulation is an unimportant influence after intake of marihuana cannot be generalized beyond the context of this study. What may be concluded is that no association between effects can be detected in sucrose consumption, yet the specificity of marihuana's effects is unclear in this study. We are unable to suggest that both internal and external stimulation can produce effects in rats who have been given marihuana. To make conjectures about what sensory systems or 
- what internal mechanisms are actually involved in the animals' discomfort is also beyond the limits of this study.

The question as to what makes marihuana aversive to rats is an interesting one, and was the original motive for conducting this experiment. It is important in considering the vast interest in this drug to continue research on the effects of marihuana. The fact that something about marihuana is aversive to the rat in its initial contact with the drug, should be a source of interest for those who not only want to discover more about the drug's effects, but also about what systems in the organism are influenced by it. 


\section{BIBLIOGRAPHY}

Beck, R. C., \& Nash, R. Thirsty rats do prefer sucrose. Psychonomic Science, $1969,15,19-20$.

Bromberg, W. Marihuana intoxication: Clincal study of cannabis sativa intoxication. American Journal of Psychiatry, 1934, 91, 303-330.

Campbell, Byron A. Interaction of aversive stimulus, summation of inhibition. Journal of Experimental Psychology, 1968, 78, 181-182.

Chambers, K.C., \& Sengstake, C. B. Sex differences in the response of rats to marihuana extract distillate. Western Psychological Association, Anaheim, California, 1973.

Dietz, M. N., \& Capretta, P. J. Modification of sugar and sugar saccharine preference in rats as a function of electric shock to the mouth. Proceedings of the 75th Annual Convention of the American Psychological Association, 1967, 161-162.

Dragoin, William B. Conditioning and extinction of taste aversions with variations in intensity of the CS and UCS. Psychonomic Science, 1971, 22, 303.

Ellsmore, T.F., \& Fletcher, G. V. Delta-nine tetrohydrocannabinol: Aversive effects in rats at high doses. Science, 1972, 175, 911-912.

Garcia, J., \& Koelling, R. A relation of cue to consequence in avoidance learning. Psychonomic Science, 1966, 4, 123-124.

Garcia, J., McGowan, B. K., Ervin, F. R., \& Koelling, R. A. Cues: Their effectiveness as a function of the reinforcer. Science, 1968, 160, 794-795.

Goodman, Louis S., \& Gilman, Alfred. The pharmocological basis of therapeutics. London: The Macmillan Company, 1970, 194-195.

Hall, C.S. Emotional behavior in the rat I. Defecation and urination as measures of individual differences in emotionality. Journal of Comparative Psychology, 1934, 18, 385-403. 
Hall, C. S. Temperament: A survey of animal studies. Psychological Bulletin, $1941,38,909-943$.

Hays, William L. Statistics for the social sciences. New York: Holt Rinehart and Winston Inc., 1973, 457-524.

Isbell, H., Gorodetzky, C. W., Jasinski, D. et al. Effects of $(-)$ delta-nine trans-tetrahydrocannabinol in man. Psychopharmocologia, 1967, 11, 184-188.

Keeler, M. Adverse reaction to marihuana. American Journal of Psychiatry, $1967,124,674-677$.

Nachman, M., \& Ashe, John R. Learned taste aversions in rats as a function of dosage, concentration, and route of administration of $\mathrm{LiCl}$. Physiology and Behavior, 1973, 10, 73.

Revusky, S. H. Aversion to sucrose produced by contingent $X$-irradiation. Journal of Comparative and Physiological Psychology, 1968, 65, 17-22.

Revusky, S., \& Garcia, J. Learned associations over long delays. In G. H. Bower (Ed.), The psychology of learning and motivation, IV. New York: Academic Press, 1970, 1-84.

Rodgers, Willard, \& Rosin, Paul. Novel food preferences in thianine deficient rats. Journal of Comparative and Physiological Psychology, 1966, 61, $1-4$.

Smith, J. C., \& Roll, D. L. Trace conditioning with $X$-rays as the aversive stimulus. Psychonomic Science, 1967, 9, 11-12.

Tart, Charles T. Work with marihuana II. Sensations. Psychology Today, 1971, $4,41-44,66-68$.

Wetle, Terrie. The effects of marihuana extract distillate on eating behavior of rats. Masters Thesis, 1971.

Winer, B. Statistical principles in experimental design. New York: McGraw Hill, 1962, 514-599. 